\title{
Day occupation is associated with psychopathology for adolescents and young adults with Down syndrome
}

Kitty-Rose Foley ${ }^{1,2,3}$, Peter Jacoby ${ }^{1}$, Stewart Einfeld ${ }^{4,5}$, Sonya Girdler ${ }^{1,2,6}$, Jenny Bourke ${ }^{1}$, Vivienne Riches ${ }^{7}$ and Helen Leonard ${ }^{1 *}$

\begin{abstract}
Background: Young adults with Down syndrome experience increased rates of emotional and behavioural problems compared with the general population. Most adolescents with Down syndrome living in Western Australia participate in sheltered employment as their main day occupation. Relationship between day occupation and changes in behaviour has not been examined. Therefore, the aim of this research was to explore any relationship between post school day occupations and changes in the young person's behaviour.

Methods: The Down syndrome Needs Opinion Wishes database was used for case ascertainment of young adults aged 15 to 32 years with Down syndrome. Families of 118 young people in this population-based database completed questionnaires in 2004, 2009 and 2011. The questionnaires addressed both young person characteristics such as age, gender, presence of impairments, behaviour, functioning in activities of daily living, and family characteristics such as income and family functioning. Post-school day occupations in which the young people were participating included open and sheltered employment, training and day recreation programs. Change in behaviour of young adults who remained in the same post-school day occupation from 2009 to $2011(n=103)$ were examined in a linear regression model adjusting for confounding variables including age, gender, prior functioning and behaviour in 2004 and family income.
\end{abstract}

Results: In comparison to those young adults attending open employment from 2009 to 2011, those attending day recreation programs were reported to experience worsening in behaviour both in the unadjusted (effect size $-0.14,95 \% \mathrm{Cl}-0.24,-0.05$ ) and adjusted models (effect size $-0.15,95 \% \mathrm{Cl}-0.29,-0.01$ ).

Conclusions: We found that the behaviour of those participating in open employment improved compared to those attending other day occupations. Further examination of the direction of this association is required.

Keywords: Intellectual disability, Down syndrome, Participation, Employment, Psychopathology, Behaviour

\section{Background}

People with intellectual disabilities are at a higher risk of experiencing behavioural, emotional and psychiatric problems than the general population [1-3]. In an Australian study, approximately 40 percent of young people with intellectual disability aged 4 to 18 years were found to have severe emotional and behavioural disorders with a subsequent longitudinal study finding that psychopathology persisted over time [1,4]. People with

\footnotetext{
* Correspondence: Helen.Leonard@telethonkids.org.au

'Telethon Kids Institute, University of Western Australia, Perth, Australia Full list of author information is available at the end of the article
}

Down syndrome have been reported to experience fewer behavioural and emotional disturbances than others with intellectual disability [5,6], yet still more than the general population [7]. Examination of agerelated changes in behaviour of children and young people with Down syndrome revealed that externalising behaviours (dominant, opposing, impulsive) were more common in five to ten year olds and internalising behaviours (lacking in self-confidence/shy and insecure) more common in adolescents and adults (10 to 30 years) [8].

Behaviour problems have been found to be associated with poorer outcomes for young people with 
intellectual disability and to have a negative impact on social participation. Those in whom more behaviour problems have been reported were more likely to have activity limitations in communication, self-care and community skills [9-11]. They were also more likely to have difficulties forming and maintaining friendships and to spend fewer hours in education each month $[12,13]$. Moreover, poorer family outcomes have been reported for the families of those who have more behavioural problems. These include poorer family quality of life, family functioning and poorer maternal mental health [14-19].

According to social learning theory behaviour is learned through modelling, observing and imitating others [20]. One such place where this modelling, observing and imitating can occur is a person's social environment within the workplace. Young people with intellectual disability who participate in different day occupations have varied opportunities to model, observe and imitate behaviours from peers [20]. Theorists have highlighted how changes in life-course, such as transitions, can impact on behaviour [21]. They discuss how relationships with peers and parents and participation in activities such as post-school day occupations can positively or negatively influence behaviour. The different day occupations in which young people with intellectual disability participate provide varied social environments and opportunities for modelling of behaviour, participating in activities and forming relationships with peers. These factors all have the potential to positively or adversely influence change in behaviour for young people with Down syndrome.

Post school day occupations for young people with intellectual disability in Australia include the following; open employment, i.e. work in a mainstream setting often with support; training, i.e. further education such as Technical and Further Education (TAFE); sheltered employment, i.e. work in a segregated setting for people with disabilities currently referred to as 'Australian Disability Enterprises' in Australia; Alternatives to Employment (ATE), i.e. a day recreation program specifically designed for people with disabilities who are unable to participate in employment or further training or; remaining at home with family or peers [10]. According to the Australian Institute of Health and Welfare in 2011 people with intellectual disabilities constitute $30 \%$ of the users of disability support services in Australia with $76 \%$ of those being under the age of 45 years [22]. They are able to access one of two government employment services 1 ) open employment services to access paid employment in the open labour market or 2) 'supported employment' services to access sheltered employment. Of all those who access the open employment services only $12 \%$ had an intellectual disability compared to $69 \%$ of those accessing the 'supported employment' services. Expenditure on disability support services has increased since 2005-2006, specifically community support services (by $80 \%$ ) and employment support services (by $47 \%)$. Over the past ten years the participation of young people with intellectual disability in sheltered employment has increased by $25 \%$. Participation in state government funded community access non-work programs such as 'Alternatives to Employment' (ATE) has also increased by $18 \%$. However, the number of young people with intellectual disability participating in open employment has remained stagnant over this same time period [23], regardless of the reported $47 \%$ increase of expenditure on employment services since 2005 [22].

Identifying behaviour management strategies to reduce stress and enhance well-being for young people with Down syndrome has been highlighted as an important focus for research $[2,24,25]$. We know that the social environment can influence the behaviour of typically developing people [20], suggesting that the behaviour of young people with Down syndrome may also be influenced by different social environments, such as different day occupations (e.g. sheltered employment versus open employment). Therefore, the aim of our research was to explore the relationship between post school day occupations and young person's change in behaviour.

The International Classification of Functioning, Disability and Health (ICF) is an internationally recognised framework for classifying health conditions, health related states and health outcome measurement [26]. Its usefulness for research in the field of intellectual disability has been well recognized [10,27-30]. Investigating complex experiences such as the relationship between behaviour and participation in day occupation taking into account the influence of environmental factors can present challenges. On this account, we have used the ICF to frame this research in order to examine these complex associations in a structured manner.

\section{Methods}

The Down syndrome "Needs Opinions Wishes" database is a population-based source of young people with Down syndrome residing in Western Australia. This study focused on young people, ascertained from this database, aged 15 to 32 years in 2009, whose parents completed questionnaires at two time points: 2009 and 2011 (response fractions were $89 \%, 93 \%$, respectively). Only those young adults who were post school in $2009(\mathrm{n}=$ 164) and/or $2011(n=180)$ were included in this study as we were interested in the relationship between postschool occupations and behaviour. A previous questionnaire in 2004 was used to obtain prior behaviour scores which were used in analysis to adjust for previous behaviour levels. There were 118 families whose sons and daughters were post school in 2009 and 2011 and who 
returned the questionnaire at all three time points. This number was further restricted to those young people who remained in the same day occupation from 2009 to 2011 $(n=103)$ to explore if there was a relationship between change in behavior and post-school day occupations.

Data were collected in the form of questionnaires containing two parts. Part one pertained to the young person's characteristics including age, gender, behavioural problems and functioning in activities of daily living (ADLs) and part two asked about family characteristics. The measures which were included in the questionnaire and are relevant for this study are classified within the components of the ICF. The relationships between the measures and the specific codes of the ICF for each component are shown in Figure 1.

\section{Body functions and structures}

Behavioural and emotional problems were measured using the Developmental Behaviour Checklist (DBC), the 96-item child version in 2004 [31] and the 107-item adult version in 2009 and 2011 [32]. The DBC was specifically developed for people with developmental and intellectual disabilities with each behavioural response being scored 0 (not true as far as you know), 1 (somewhat or sometimes true) or 2 (very true or often true). The $\mathrm{DBC}-\mathrm{C}$ has proven convergent validity, high inter-rater reliability between teachers and parents, high test-retest reliability and sensitivity to change [31]. The DBC-A has been found to have acceptable test-retest and inter-rater reliability and convergent ability has been demonstrated with two measures of behavioural disturbances of adults with intellectual disability [33]. The DBC-A and DBC-C were scored in three ways for this study which enables them to be comparable [34]; 1) Mean Item Score (MIS) reflecting the overall behaviour problems 2) Proportion of Items Checked (PIC) which is the proportion of items checked a one or a two and measures range of problem behaviours exhibited, 3) the Intensity Index (II) which is the proportion of items checked 2, out of all the items checked 1 or 2 which measures the severity of the problem behaviours.

\section{Activity}

In the 2004 questionnaires, the Functional Independence Measure (WeeFIM), modified for questionnaire use as previously used $[19,35]$, was included to measure functioning in activities of daily living [36]. The original WeeFIM has good inter-rater reliability and concurrent validity with the Pediatric Evaluation of Disabilities Inventory in children with developmental disabilities [37].

\section{Participation and environment factors}

Day occupation is one aspect of the participation component of the ICF, identifying involvement in the different occupations. It is also associated with environment factors as the social and physical environment of the occupation could influence the young adults. Post school day occupations in which the young adults were participating in 2009

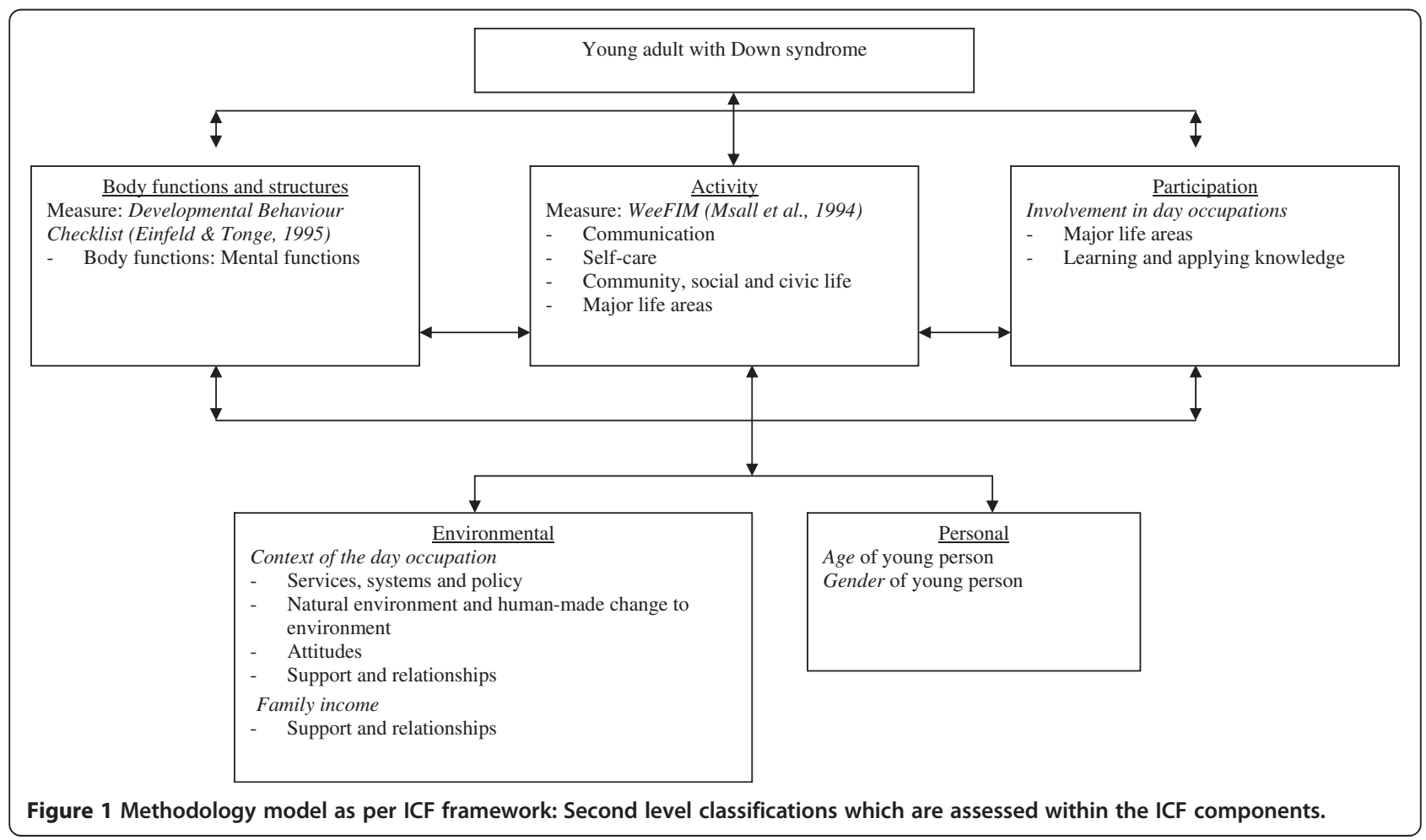


and 2011 were categorised according to open employment, training, sheltered employment or day recreation programs describing Alternatives to Employment (ATE) programs.

\section{Personal factors}

Personal factors including date of birth and gender of the young adult with Down syndrome are ascertained from the database.

\section{Data analysis}

Descriptive statistics including analysis of variance and chi-squared tests were used to describe the univariate relationship between independent variables and the outcome, change in problem behaviours from 2009 to 2011, for those who remained in the same day occupation from 2009-2011. Descriptive statistics were also used to describe the problem behaviour scores at each time point across the different post-school day occupations.

A linear regression model with change in behaviour from 2009 to 2011 as the outcome was used in the final model allowing adjustments for confounding variables. These included; age, gender, family income, previous functioning in activities of daily living and previous problem behaviour score. Unadjusted and adjusted models were reported separately. STATA 11 was used for these analysis [38].

\section{Results}

\section{Participant characteristics}

Of the young adults who were post school in 2009 ( $\mathrm{n}=$ 164) and/or $2011(\mathrm{n}=180), 143(87 \%)$ had returned questionnaires at both time points. Of these 143, 118 individuals had also returned a questionnaire in 2004 when information on previous behaviours and functioning was utilised. For the 118, their ages ranged from 10 to 24 years in 2004 (mean 17.2 SD 4.3), 51 (43.2\%) were female and $67(56.8 \%)$ were male. It was noted that a number of individuals had left school in 2009 at younger than usual ages of 15-17 years. Out of the 118, there were 103 individuals who met the study criteria of being post-school, and remaining in the same day occupation from 2009 to 2011 and whose parents had also completed questionnaires in 2004.

\section{Relationship between post-school day occupations and change in behaviour problems}

The day occupations of all young adults, who returned a questionnaire in 2009 and/or 2011, are shown in Table 1. Of the 103 young adults who remained in the same day occupation from 2009 to 2011, those attending day recreation programs were reported as having the poorest behaviour in 2009 in terms of range (PIC) (mean 0.30 SD 0.16), intensity (II) (mean 0.38 SD 0.21) and overall
Table 1 Day occupations of all young adults who were post-school and returned questionnaires in 2009 and/or 2011

\begin{tabular}{llll}
\hline Day occupation & $\mathbf{2 0 0 9}(\%)$ & $\mathbf{2 0 1 1}(\%)$ & Remained \\
\hline Open employment & $42(25.6)$ & $40(22.2)$ & $27(26.2)$ \\
Training & $17(10.4)$ & $23(12.8)$ & $8(7.8)$ \\
Sheltered employment & $64(39.0)$ & $75(41.7)$ & $46(44.7)$ \\
Day recreation programs & $41(25.0)$ & $38(21.1)$ & $22(21.4)$ \\
Remained at home & $0(0)$ & $4(2.2)$ & - \\
Total & $164(100)$ & $180(100)$ & $103(100)$ \\
\hline
\end{tabular}

score (MIS)(mean 0.41 SD 0.25). From 2009 to 2011, the range (PIC $(\mathrm{t}(21)=-2.49, \mathrm{p}=0.02)$ ) and overall score (MIS $(\mathrm{t}(21)=-1.98, \mathrm{p}=0.06)$ of behaviour problems of young adults participating in day recreation programs increased but the intensity (II $(\mathrm{t}(21)=0.39, \mathrm{p}=0.70)$ ) remained relatively stable (Table 2). In 2011, 45.5\% ( $\mathrm{n}=$ 10) of the young adults attending day recreation programs reported MIS scores beyond the cut-off point for psychiatric caseness, meaning a full psychiatric assessment is recommended [32].

Young adults attending open employment in 2009 were reported as having the fewest behavioural problems in terms of range (PIC (mean 0.14, SD 0.11)) and overall score (MIS (mean 0.16 SD 0.13)) and those attending training had the lowest intensity (II (mean 0.12 SD 0.15)) of behavioural problem. The range $(\mathrm{PIC}(\mathrm{t}(26)=2.07, \mathrm{p}=0.049))$ and overall (MIS $(\mathrm{t}(26)=2.58, \mathrm{p}=0.016)$ ) scores for those attending open employment decreased significantly from 2009 to 2011 . The range (PIC $(\mathrm{t}(45)=1.78$, $\mathrm{p}=0.08)$ ), intensity (II $(\mathrm{t}(44)=0.87, \mathrm{p}=0.54))$ and overall score (MIS $(\mathrm{t}(45)=1.61, \mathrm{p}=0.11)$ ) for behaviour problems in those attending sheltered employment showed a similar but not significant trend to decrease from 2009 to 2011 (Table 2).

\section{Adjusted model}

Change in behaviour from 2009 to 2011 was converted to a change score for the regression model, where a positive number referred to an improvement in behaviour (Table 3). Confounding variables which were adjusted for included age in 2004, gender, family income, functioning in activities of daily living (ADL) in 2004 and problem behaviours (DBC continuous score) in 2004. The effect size in the table reflects a per point change in overall behaviour MIS compared to the change in behaviour of those attending open employment. In comparison to those young adults attending open employment from 2009 to 2011, those attending day recreation programs experienced significant worsening in behaviour both in the unadjusted (effect size -0.14 , 95\% CI -0.24, -0.05) and adjusted models (effect size $-0.15,95 \%$ CI $-0.29,-0.01$ )(Table 3 ). 
Table 2 Mean scores of problem behaviour scores in 2009 and 2011

\begin{tabular}{|c|c|c|c|c|c|c|c|c|c|c|}
\hline \multirow[b]{3}{*}{ Day occupations } & \multirow[b]{3}{*}{ Freq } & \multicolumn{9}{|c|}{ Problem behaviour scores } \\
\hline & & \multicolumn{3}{|c|}{$\begin{array}{c}\text { Proportion items checked } \\
\text { (range of behaviour problems) }\end{array}$} & \multicolumn{3}{|c|}{$\begin{array}{l}\text { Intensity index (severity } \\
\text { of behaviour problems) }\end{array}$} & \multicolumn{3}{|c|}{ Mean item score } \\
\hline & & 2009 M, SD & $2011 \mathrm{M}, \mathrm{SD}$ & $\overline{p-v a l u e}$ & 2009 M, SD & 2011 M, SD & $\overline{p \text {-value }}$ & 2009 M, SD & $2011 \mathrm{M}, \mathrm{SD}$ & p-value \\
\hline Open & 27 & $0.14,0.11$ & $0.11,0.10$ & 0.049 & $0.15,0.16$ & $0.10,0.22$ & 0.317 & $0.16,0.13$ & $0.11,0.10$ & 0.016 \\
\hline Training & 8 & $0.19,0.15$ & $0.22,0.05$ & 0.446 & $0.12,0.15$ & $0.15,0.13$ & 0.173 & $0.22,0.21$ & $0.25,0.18$ & 0.574 \\
\hline Sheltered & 46 & $0.20,0.15$ & $0.17,0.13$ & 0.081 & $0.21,0.20$ & $0.19,0.19$ & 0.535 & $0.25,0.19$ & $0.21,0.17$ & 0.114 \\
\hline Day recreation programs & 22 & $0.30,0.16$ & $0.36,0.12$ & 0.021 & $0.38,0.21$ & $0.38,0.24$ & 0.982 & $0.41,0.25$ & $0.50,0.35$ & 0.061 \\
\hline
\end{tabular}

Note: Higher behaviour score refers to poorer behaviour from 2009 to 2011.

Note: Cut-off score for psychiatric caseness MIS $=0.48$.

We examined the change in behaviour of the young adults who were in open employment or day recreation programs at the 2009 time point but were not in the same occupation in 2011. We were interested to compare the behaviour change patterns of those young adults who did not remain in the same day occupation with those who did. We found that the patterns were similar for those who remained in open employment (mean change 0.05, SD 0.10) and those that changed from open employment to a different day occupation (mean change -0.02 SD 0.17) $(\mathrm{p}$-value $=0.14)$. However, the behavior of those who remained in day recreation programs deteriorated (mean change -0.09 SD 0.22) compared with those that moved out of day recreation programs into a different day occupation (mean change 0.05 SD 0.14) $(\mathrm{p}=0.05)$.

\section{Discussion}

Adolescents and young adults with Down syndrome attending open employment for two consecutive years were found to experience a decline in behaviour problems in terms of range, intensity and overall problems, after adjusting for known confounding variables. Those attending sheltered employment for two years also experienced a decline in problem behaviours in range, intensity and overall behaviour problems, but this was less marked than for those in open employment. Young adults who were attending day recreation programs for two years experienced an increase in range, intensity and overall behaviour problems. At the second time point almost half of these young adults' behaviour problems were reported to be beyond the clinical cut-off score for psychiatric caseness [32].

A considerable strength of this paper is the use of the DBC to measure emotional and behavioural problems at three time points. The use of the child version and the adult version ensures that the questionnaire remains applicable and valid. Scoring the range and intensity of emotional and behavioural problems adds a particularly clinically relevant interpretation of the data which could not be ascertained from only scoring the overall total [34]. It allows us to recognize the type of behaviour changes which then provides more detailed information to guide development of intervention. A limitation of this study relates to the fact that those young people who move out of open employment could do so because of deteriorating behaviour, which could contribute to the improved behaviour seen in the group who remain. However, when we investigated this we found that there was no difference in the changes in behaviour of those that remained and those that left open employment. However, we did find that for those who left the day recreation programs behaviour improved significantly in comparison to those who remained in day recreation programs. We cannot definitely state whether these young people's behaviour improved because they left the day recreation programs or they left because their behaviour improved. Another potential limitation of this study is that the data are parent report. Research in the general population has indicated that there may be discordance between parent and young person reporting of emotional and behavioural problems, specifically in

Table 3 Linear regression models of behaviour change scores from 2009 to 2011 by day occupation

\begin{tabular}{|c|c|c|c|c|c|c|c|}
\hline & & \multicolumn{3}{|c|}{ Unadjusted $(n=103)$} & \multicolumn{3}{|c|}{ Adjusted model $(n=69)$} \\
\hline & & Effect size $^{\dagger}$ & $95 \% \mathrm{Cl}$ & $P$ value & Effect size $^{+}$ & $95 \% \mathrm{Cl}$ & P Value \\
\hline \multirow[t]{4}{*}{ Mean item scores } & Open employment & Baseline & & & Baseline & & \\
\hline & Training & -0.08 & $-0.21,0.05$ & 0.217 & -0.10 & $-0.23,0.04$ & 0.152 \\
\hline & Sheltered employment & -0.01 & $-0.09,0.06$ & 0.728 & -0.01 & $-0.10,0.09$ & 0.894 \\
\hline & Day recreation programs & -0.14 & $-0.24,-0.05$ & 0.002 & -0.15 & $-0.29,-0.01$ & 0.034 \\
\hline
\end{tabular}

Note: Variables in adjusted model: age, gender, family income (imputed variable), functioning in 2004, behaviour in 2004.

Note: Positive behaviour score refers to an improvement in behaviour from 2009 to 2011.

${ }^{\dagger}$ Effect size is the estimated difference in the behaviour change score between each group and the reference group (open employment). 
regards to internalizing behaviours and when the parent experiences psychopathological issues [39-41]. However, challenges gaining self-report data from young people with intellectual disability have been acknowledged and the need for appropriate and psychometrically rigorous instruments for young people with intellectual disability to report their own emotions and behaviours has been highlighted $[42,43]$. It is important to investigate the potential influence that participation in open employment could have on behavioural and emotional problems of young adults with Down syndrome. Although, we cannot definitively confirm any causal relationship between day occupation and change in behaviour over time, our study would suggest that further scrutiny of this association is needed. More detailed information on the length of time spent within particular jobs may also help elucidate the factors affecting behaviour.

We found that participation in open employment was associated with an improvement in behaviour over time compared to other day occupations. This association could be attributed to many different factors such as the modeling of positive behaviours from typically developing peers or the satisfaction of participation in a meaningful, mainstream occupation. The idea that the behavior of young people who are attending open employment improves as a result of modeling, observing and imitating the behavior of their typically developing peers is supported by the theory of social learning [20]. Research has shown that young people with intellectual disability who participate in open employment experience greater perceptions of job clarity and are provided more opportunities for socialization than those participating in day recreation programs or sheltered employment [44,45]. Previous research has already shown that there are positive associations between participation in open employment and social and activity related outcomes and that young people with intellectual disability have a desire to have the opportunity to participate in the open labour market $[46,47]$. Despite this evidence and the significant increase in expenditure on employment services for people with disabilities in Australia, there has not been a change in the number of people with intellectual disability participating in open employment in Australia over the past ten years [22,23].

In relation to sheltered employment, our results showed a trend towards improving behaviour over the two year time period. Martorell, Gutierrez-Recacha, Pereda and Ayuso-Mateos (2008) examined behaviour of young people involved in sheltered employment and day recreation services through a cross-sectional study and concluded that those participating in sheltered employment reported less problem behaviours compared to those attending day recreation services. However, people who were attending open employment were not included in their study and the authors proposed that behaviour problems "preclude a good functioning, hence causing a worse work outcome" [48]. We suggest that the direction of this relationship has not been proven and perhaps young people who have more problem behaviours could decrease problem behaviours through participation in open employment. In a further adjusted analysis Martorell and colleagues showed that the influence of behaviour was ameliorated by the inclusion of a variable describing selfdetermination. Self-determination has been reported to occur with more normalized, community-based environments for people with intellectual disability, such as an open employment context [49,50].

In our study the young adults who were attending day recreation programs for two consecutive years showed a concerning increase in range of problem behaviours and overall problem behaviours. This could be attributed to lack of choice-making opportunities, isolation and segregation from the community and lack of meaningful and challenging activities within the day recreation programs. These young adults showed a significant increase in range of problem behaviours but not intensity. This also suggests that the young adults who were attending day recreation programs may have modelled undesirable behaviours from their peers in the day recreation programs environment which would increase the range of problems they exhibit and not alter the intensity. Additionally, almost half of those young adults attending day recreation programs for two years had reported problem behaviour scores beyond the clinical cut-off for a psychiatric case. The developers of the DBC recommend a comprehensive psychiatric assessment is recommended for those young adults who scored beyond the cut-off score [32]. The stated aims of day recreation programs include support outcomes related to social participation, increasing independence, lifelong learning and enhanced support networks [51]. The findings from this study must be interpreted in the context of the limitations of the study, yet definitely warrant further examination of whether the aims of the day recreation programs are currently being met.

Framing this research within the ICF allows for investigation of the ICF components which have an association with change in behaviour for young people with intellectual disability. This research has highlighted the potential for environmental factors (i.e. context of the day occupations) to modify behavioural disturbances in young adults with Down syndrome. We cannot confirm the direction of the relationship between change in behaviour and day occupation. However our findings do raise specific questions about the potential mechanisms underlying these. We also found a trend towards decreasing problem behaviours for young adults who were attending sheltered employment compared to other day 
occupations. The main difference between a sheltered employment environment and a day recreation program environment is participation in an organized task and adherence to routines and clearly defined rules for safety, dress and behaviour. The increase in problem behaviours in those young adults participating in day recreation programs compared to those participating in sheltered employment suggests that the activity of undertaking specific tasks in the sheltered employment environment could be playing a role in decreasing problem behaviours for those young people. The sheltered employment environment could also create an opportunity for steady friendships which could have a positive influence on behaviour. These points highlight the relationship between the participation component of the ICF and the impairments of body functions and structures component. They also provide valuable information about the importance of environmental factors and participation when considering the psychopathology of young people with Down syndrome.

\section{Conclusion}

The problem of psychopathology has been reported as both substantial and persistent for young people with intellectual disability and the need for effective mental health interventions is paramount [4]. This study has identified an association between improvements in behavior problems and participation in open employment for young people with Down syndrome, while adjusting for known confounding variables. This finding provides information which could be helpful when developing mental health interventions for young people with Down syndrome. This study is one of the first, to the authors' knowledge, to investigate the relationship between behavioural change and specific post-school day occupations. The longitudinal nature of the study adds strength as well as the fact that case ascertainment occurred from a population-based database. Future research should focus on identifying the specific mechanisms within an open employment setting which could positively influence behaviour change.

\section{Competing interests}

The authors declare that they have no competing interests.

\section{Authors' contributions}

$\mathrm{HL}, J B, S E, K F$ and $S G$ participated in the design of the study and $H L, J B$ and $\mathrm{KF}$ in collection of data. $\mathrm{HL}, \mathrm{PJ}$ and $\mathrm{KF}$ planned analyses and KF carried out analyses. KF, HL, JB, SG were involved in drafting the manuscript and interpreting results and VR, SE and PJ in critically revising it. All authors read and approved the final manuscript.

\section{Acknowledgements}

Ethical approval for the study was obtained from the Ethics Committee of the Women's and Children's Health Services in Western Australia. We thank the families for their participation and the Disability Services Commission of WA for facilitating the distribution of questionnaires. We also gratefully acknowledge the initial seed funding from Australian Research Alliance for
Children and Youth and the ongoing funding provided by the Australian Research Council. \#LP0989847 for the project 'Leaving School: Maximizing participation and life outcomes in youth with an intellectual disability transitioning from secondary school to adult life'. We would also like to acknowledge all our industry partners Down syndrome WA, Disability Services Commission, Edge Employment Solutions and Department of Education WA and the contributing investigators on the grant: Carol Bower, Bruce Tonge and Nicholas de Klerk.

\section{Author details}

'Telethon Kids Institute, University of Western Australia, Perth, Australia. ${ }^{2}$ School of Exercise and Health Sciences, Edith Cowan University, Perth, Australia. ${ }^{3}$ Department of Developmental Disability Neuropsychiatry, School of Psychiatry, The University of New South Wales, Sydney, Australia. ${ }^{4}$ Faculty of Health Sciences, University of Sydney, Sydney, Australia. ${ }^{5}$ Brain and Mind Research Institute, University of Sydney, Sydney, Australia. ${ }^{6}$ School of Occupational Therapy and Social Work, Centre for Research into Disability and Society, Curtin Health Innovation Research Institute, Curtin University, Perth, Western Australia, Australia. ${ }^{7}$ Centre for Disability Studies, The University of Sydney, Sydney, Australia.

Received: 4 October 2013 Accepted: 10 September 2014

Published online: 03 October 2014

\section{References}

1. Einfeld SL, Tonge BJ: Population prevalence in children and adolescents with intellectual disabilities: II epidemiological findings. J Intellect Disabil Res 1996, 40:99-109.

2. Dykens EM: Psychiatric and behavioural disorders in persons with Down syndrome. Ment Retard Dev Disabil Res Rev 2007, 13:272-278.

3. Paschos D, Bouras N: Mental health supports in developmental disabilities. In Handbook of Developmental Disabilities. Edited by Odom SL, Horner RH, Snell ME, Blacher J. New York: Guilford; 2007:483-500.

4. Einfeld SL, Piccinin AM, MacKinnon A, Hofer SM, Taffe J, Gray KM, Bontempo $D E$, Hoffman LR, Parmenter T, Tonge BJ: Psychopathology in young people with intellectual disability. J Am Med Assoc 2006, 296(16):1981-2682.

5. Mantry D, Cooper SA, Smiley E, Morrison J, Allan L: The prevalence and incidence of mental ill-health in adults with Down syndrome. J Intellect Disabil Res 2008, 52:141-155.

6. Cooper SA, Speck R: Epidemiology of mental ill health in adults with intellectual disabilities. Curr Opin Psychiatry 2009, 22:431-436.

7. Fidler DJ, Most DE, Booth-Laforce C, Kelly JF: Temperament and behaviour problems in young children with Down syndrome at 12, 30, and 45 months. Downs Syndr Res Pract 2006, 10:23-29.

8. Nicham R, Weitzdorfer R, Hauser E, Feidl M, Schubert M, Wurst E, Lubec G, Seidl R: Spectrum of cognitive, behavioural and emotional problems in children and young adults with Down syndrome. J Neural Transm Suppl 2003, 67:173-191.

9. Danquah A, Limb K, Chapman M, Burke C, Flood A, Gore S, Greenwood K, Healey K, Reid WK, Kilroy J, Lacey H, Malone C, Perkin M, Hare DJ: An investigation of factors predictive of continued self-injurious behaviour in an intellectual disability service. J Appl Res Intellect Disabil 2009, 22:395-399.

10. Foley K-R, Jacoby P, Girdler S, Bourke J, Pikora T, Lennox N, Einfeld SL, Llewellyn G, Parmenter T, Leonard H: Functioning and post-school transition outcomes for young people with Down syndrome. Child Care Health Dev 2013, 39(6):789-800.

11. Papazoglou A, Jacobson LA, Zabel TA: More than intelligence: distinct cognitive/behavioural clusters linked to adaptive dysfunction in children. J Int Neuropsychol Soc 2013, 19:189-197.

12. Farmer TW: Misconceptions of peer rejection and problem behaviour: understanding aggression in students with mild disabilities. Remedial Spec Educ 2000, 21:194-208.

13. White DA, Dodder RA: The relationship of adaptive and maladaptive behaviour to social outcomes for individuals with developmental disabilities. Disabil Soc 2000, 15(6):897-908.

14. Glidden LM: Family well-being and children with intellectual disability. In The Oxford Handbook of Intellectual Disability and Development. Edited by Burack JA, Hodapp RM, Larocci G, Zigler E. Oxford, UK: Oxford University; 2012:303-317

15. Foley K-R, Girdler S, Downs J, Jacoby P, Bourke J, Lennox N, Llewellyn G, Parmenter T, Leonard H: Family quality of life is associated with the day 
occupations of young people with Down syndrome. Soc Psychiatry Psychiatr Epidemiol 2014, 49:1455-1465.

16. Povee $K$, Roberts J, Bourke J, Leonard $H$ : Family functioning in families with a child with Down syndrome: a mixed methods approach. J Intellect Disabil Res 2012, 56:961-973.

17. Totsika V, Hastings RP, Emerson E, Lancaster GA, Berridge DM: A population-based investigation of behavioural and emotional problems and maternal mental health: associations with autism spectrum disorder and intellectual disability. J Child Psychol Psychiatry 2011, 52(1):91-99.

18. Hastings RP, Beck A: A practitioner review: stress intervention for parents of children with intellectual disabilities. J Child Psychol Psychiatry 2004, 45:1338-1349.

19. Bourke J, Ricciardo B, Bebbington A, Aiberti K, Jacoby P, Dyke P, Msall M, Bower $\mathrm{C}$, Leonard $\mathrm{H}$ : Maternal physical and mental health in children with Down syndrome. J Pediatrics 2009, 153(3):320-326.

20. Wuang YP, Chwen-Yng S: Patterns of participation and enjoyment in adolescents with Down syndrome. Res Dev Disabil 2012, 33:841-848.

21. United Nations: Incheon Strategy to "Make the Right Real" for Persons with Disabilities in Asia and Pacific. Bangkok: United Nations ESCAP; 2012

22. Australian Institute of Health and Welfare: Disability support services: services provided under the National Disability Agreement 2010-11. In AlHW Disability Series. Canberra: Australian Government; 2010.

23. Tuckerman $\mathrm{P}$, Cain $\mathrm{P}$, Long B, Klarkowski J: An exploration of trends in open employment in Australia since 1986. J Vocational Rehabil 2012, 37:173-183.

24. Cooper C, Smiley E, Morrison J, Williamson A, Allan L: Mental ill-health in adults with intellectual disabilities: prevalence and associated factors. Br J Psychiatry 2007, 190:27-35.

25. Smiley E: Epidemiology of mental health problems in adults with learning disability: an update. Adv Psychiatr Treat 2005, 11:214-222.

26. World Health Organization: ICF: International classification of functioning, disability and health. 1st edition. Geneva: World Health Organisation; 2001.

27. Arvidsson P, Granlund M, Thyberg M: Factors relating to self-rated participation in adolescents and adults with mild intellectual disability - a systematic literature review. J Appl Res Intellect Disabil 2008, 21:277-291.

28. Foley K-R, Dyke P, Girdler S, Bourke J, Leonard H: Young adults with intellectual disability transitioning from school to post-school: a literature review framed within the ICF. Disabil Rehabil 2012, 20(34):1747-1764.

29. Jelsma J: Use of the international classification of functioning, disability and health: a literature survey. J Rehabil Med 2009, 41:1-12.

30. Verdonschot MML, de Witte LP, Reichrath E, Buntinx WHE, Curfs LMG: Impact of environmental factors on community participation of persons with an intellectual disability: a systematic review. J Intellect Disabil Res 2009, 53(1):54-64.

31. Einfeld SL, Tonge BT: The Developmental Behavior Checklist: the development and validation of an instrument to assess behavioral and emotional disturbance in children and adolescents with mental retardation. J Autism Dev Disord 1995, 25:81-104.

32. Mohr C, Tonge BJ, Einfeld SL, Taffe J: The developmental behaviour checklist for adults (DBC-A) Revised. Sydney, Australia: University of Sydney and Monash University; 2011.

33. Mohr C, Tonge BJ, Einfeld SL: The development of a new measure for the assessment of psychopathology in adults with intellectual disability. J Intellect Disabil Res 2005, 49(7):469-480.

34. Taffe J, Tonge BJ, Gray KM, Einfeld SL: Extracting more information from behaviour checklists by using components of mean based scores. Int J Methods Psychiatr Res 2008, 17(4):232-240.

35. Leonard S, Msall M, Bower C, Tremont M, Leonard H: Functional status of school-aged children with Down syndrome. J Paediatr Child Health 2002, 38:160-165.

36. Msall ME, DiGaudio K, Rogers BT, LaForest S, Catanzaro NL, Campbell J, Wilczenski F, Duffy LC: The Functional Independence Measure for Children (WeeFIM): conceptual basis and pilot use in children with developmental disabilities. Clin Pediatr 1994, 33(7):421.

37. Ziviani J, Ottenbacher KJ, Shephard K, Foreman S, Astbury W, Ireland P: Concurrent validity of the functional independence measure for children (WeeFIM) and the pediatric evaluation of disabilities inventory in children with developmental disabilities and acquired brain injuries. Phys Occup Ther Pediatr 2001, 21(1/3):91-101.

38. Statacorp: Stata Statistical Software. In Release 80. College Station, Texas: Stata Corporation; 2003.
39. Treutler CM, Epkins CC: Are discrepancies among child, mother, and father reports on children's behaviour related to parents' psychological symptoms and aspects of parent-child relationships? J Abnorm Child Psychol 2003, 31(1):13-27.

40. Ferdinand RF, van der Ende J, Verhulst FC: Parent-adolescent disagreement regarding psychopathology in adolescents from the general population as a risk factor for adverse outcome. J Abnorm Psychol 2004, 113(2):198-206.

41. Hughes EK, Gullone E: Discrepancies between adolescent, mother, and father reports of adolescent internalising symptom levels and their association with parent symptoms. J Clin Psychol 2010, 66(9):978-995.

42. Haynes A, Gilmore L, Shochet I, Campbell M, Roberts C: Factor analysis of the self-report version of the strengths and difficulties questionnaires in a sample of children with intellectual disability. Res Dev Disabil 2013 34:847-854

43. Douma JC, Dekker MC, Verhulst FC, Koot HM: Self-reports on mental health problems of youth with moderate to borderline intellectual disabilities. J Am Acad Child Adolesc Psychiatry 2006, 45(10):1224-1231.

44. Beyer S, Brown T, Akandi R, Rapley M: A comparison of quality of life outcomes for people with intellectual disabilities in supported employment, day services and employment enterprises. J App/ Res Intellect Disabil 2010, 23:290-295.

45. Hall AC, Kramer J: Social capital through workplace connections: opportunities for workers with intellectual disabilities. J Soc Work Disabil Rehabil 2009, 8(3):146-170.

46. Migliore A, Mank D, Grossi T, Rogan P: Integrated employment or sheltered workshops: preferences of adults with intellectual disabilities, their families, and staff. J Vocational Rehabil 2007, 26:5-19.

47. Scott M, Foley K-R, Bourke J, Leonard H, Girdler S: "I have a good life": the meaning of well-being from the perspective of young adults with Down syndrome. Disabil Rehabil 2013, 36(15):1290-1298.

48. Martorell A, Gutierrez-Recacha P, Pereda A, Ayuso-Mateos JL: Identification of personal factors that determine work outcome for adults with ID. J Intellect Disabil Res 2008, 52(12):1091-1101.

49. Wehmeyer ML, Bolding N: Enhanced self-determination of adults with intellectual disability as an outcome of moving to community-based work or living environments. J Intellect Disabil Res 2001, 45(5):371-383.

50. Wehmeyer ML, Palmer SB: Adult outcomes for students with cognitive disabilities three-years after high-school: The impact of self-determination Educ Train Develop Disabil 2003, 38(2):131-144

51. Disability Services Commission: Post school options process: pathways to the future. A state government initiative for school leavers with disabilities. Perth, Western Australia: Disability Services Commission; 2009

doi:10.1186/s12888-014-0266-z

Cite this article as: Foley et al:: Day occupation is associated with psychopathology for adolescents and young adults with Down syndrome. BMC Psychiatry 2014 14:266.

\section{Submit your next manuscript to BioMed Central and take full advantage of:}

- Convenient online submission

- Thorough peer review

- No space constraints or color figure charges

- Immediate publication on acceptance

- Inclusion in PubMed, CAS, Scopus and Google Scholar

- Research which is freely available for redistribution 